\title{
A cross-sectional evaluation of a community-orientated mental health service
}

\author{
Jon Spear, Andrew Cole and Jan Scott
}

\begin{abstract}
Community mental health services have been criticised for seeing those with minor poychiatic disorders of the expense of those with severe and long-ferm illiness. We report a cross-sectional evaluation of a UK service based entirely within the community. Most patients in contact with the service (66\%) had a psycholic disorder or an affective cilsorder. Patients with greater impoirment were llikely to recelve more intensive treatment. Only $20 \%$ of the community psychiatic nurse (CPN) case load focused on acute distress and neurotic disorders. Within this service careful operational planning and maintaining CPNs within the secondary care system appear to be critical factors in achloving the goal of ofving priority to the severely mentally ill.
\end{abstract}

Recent research (Muijen et al, 1992) suggests that early intervention and assertive outreach programmes reduce the use of in-patient facilities. Community care may also be preferred by patients and their families (Muijen et al, 1992). However there are doubts about the generalisation of results from services introduced for research purposes to general services (Thornicroft \& Bebbington, 1989).

\section{The study}

This is a census of a general mental health service which is entirely community based (Scott et al, 1992). The catchment area is in North Tyneside with a population of 50,000 (in a district ranked 58th of 192 on the Jarman deprivation indices). The service receives over 450 referrals each year. At the time of the survey, staffing consisted of a consultant/ senior lecturer, a lecturer, a psychiatric registrar, 3.5 community psychiatric nurses, two occupational therapists, a social worker and administrative support. The service liaises closely with primary care but patients are rarely seen in general practitioners' surgeries. The stand-alone community-based unit has nine beds which admit voluntary and detained patients. There is access to five back-up beds at the mental hospital but these are only used in special circumstances (on only seven occasions during 1992).

The stand-alone unit also provides a partial hospitalisation programme. As suggested by Klar et al, (1982) this provides acute psychiatric treatment, rehabilitation, support and social care (for example providing meals and social contact). Some severely impaired patients visited the unit daily (e.g. to collect medication) and had 24 hours access to nursing staff by telephone. Other facilities include day support in the community for those with long-term mental illness (e.g. a 'contact club'), a local authority day centre, a sheltered workshop and a young persons' housing project run by MIND.

The service has clearly defined aims which include a primary goal of assertively treating patients with severe and long-term mental illness and a secondary goal of providing an early intervention service to new referrals. Self referral is not encouraged although previous service users may re-refer themselves. Emergency referrals are seen by a team member within a matter of hours (minimum=15 minutes; maximum=12 hours), urgent referrals within 72 hours and routine referrals within one week. After assessment all cases are reviewed by the multidisciplinary team and allocated to the most appropriate key-worker.

The aim of this survey was to determine the case-mix of patients in contact with the service, and to describe the services allocated to each individual in terms of the setting in which treatment is provided and the keyworker's professional background.

All patients in 'active contact' with the service on December 1992 were included in the survey. 'Active contact' was defined as 
Table 1. Current global assessment of function (GAF) and treatment setting

\begin{tabular}{|c|c|c|c|c|}
\hline & \multicolumn{4}{|c|}{ Treatment selting } \\
\hline & In-pationt & Doy-patient & Domicillary & Out-pationt \\
\hline $\begin{array}{l}\text { Mean GAF } \\
\text { Range }\end{array}$ & $\begin{array}{l}38.0 \\
20-55\end{array}$ & $\begin{array}{l}53.1 \\
25-85\end{array}$ & $\begin{array}{l}57.6 \\
30-80\end{array}$ & $\begin{array}{l}59.6 \\
35-85\end{array}$ \\
\hline \multicolumn{5}{|c|}{$F(3,232)=10.2(P<0.005)^{\circ}$} \\
\hline $\begin{array}{l}\text { GAF } \\
0-40 \\
41-70 \\
71+\end{array}$ & $\begin{array}{l}6 \\
3 \\
1\end{array}$ & $\begin{array}{r}7 \\
16 \\
4\end{array}$ & $\begin{array}{r}9 \\
91 \\
11\end{array}$ & $\begin{array}{r}8 \\
54 \\
17\end{array}$ \\
\hline Total"* & 10 & 27 & 111 & 79 \\
\hline$\chi=25.2 ;$ d.f. $=$ & & & & \\
\hline
\end{tabular}

- One way analysis of variance (ANOVA)

- GAF not avallable for 8 patients

Table 2. A comparison of key-worker allocation by diagnosis and level of functioning of cases in active contact with a community mental health service

\begin{tabular}{|c|c|c|c|c|c|}
\hline & \multicolumn{5}{|c|}{ Key-worker } \\
\hline & CPN & OT & sw & Doctor & Multiple input \\
\hline $\begin{array}{l}\text { Allocation by diagnosis } \\
\text { Psychosts } \\
\text { Affectlve disorder } \\
\text { Other disorders } \\
\text { Anxiety/adjustment disorders } \\
\text { Total" }\end{array}$ & $\begin{array}{l}24 \\
26 \\
20 \\
16 \\
86\end{array}$ & $\begin{array}{l}27 \\
10 \\
10 \\
10 \\
37\end{array}$ & $\begin{array}{r}8 \\
2 \\
10 \\
5 \\
25\end{array}$ & $\begin{array}{r}34 \\
65 \\
36 \\
10 \\
145\end{array}$ & $\begin{array}{r}36 \\
22 \\
13 \\
4 \\
75\end{array}$ \\
\hline \multicolumn{6}{|l|}{$\chi^{2}=22.2 ;$ d.f.=12; $P<0.05$} \\
\hline & \multicolumn{5}{|c|}{ Key-worker } \\
\hline & CPN & or & sw & Doctor & Mulliplo Inpur \\
\hline $\begin{array}{l}\text { Allocation of GAF score } \\
\text { Mean } \\
\text { Standard deviation }\end{array}$ & $\begin{array}{l}59 \\
9.3\end{array}$ & $\begin{array}{l}64 \\
7.8\end{array}$ & $\begin{array}{l}60 \\
11\end{array}$ & $\begin{array}{l}57 \\
12\end{array}$ & $\begin{array}{l}52 \\
15\end{array}$ \\
\hline ANOVA $F(4.214)=3.8 ; P<0.02$ & & & & & \\
\hline
\end{tabular}

(CPN community psychiatric nurses; OT occupational theraplst; SW social worker; multiple input predominantly involved a CPN and a doctor)

"Excludes in-potients

face-to-face contact with a team member in the 12 weeks prior to the survey date. Patients who had been in active contact with the service but were discharged before the survey date were excluded.

Diagnoses were made using the Abbreviated Symptom Checklist and DSM-III-R (American Psychiatric Association, 1987) diagnoses were grouped into psychotic disorders (schizophrenia, schizophreniform disorder, delusional disorder, organic delusional disorder, organic hallucinosis and psychotic disorder not otherwise specified), affective disorders, anxiety adjustment disorders and other disorders (which included personality disorders, eating disorders and substance abuse). Global functioning was measured by using the Global Assessment of Functioning (GAF) which gives a score of 0-100 based on symptoms, social and occupational functioning with a low score indicating a greater need for care. A GAF score of $0-40$ is 
typical for in-patients and a score of 41-70 is typical for out-patients. The treatment settings were categorised as in-patient, partial hospitalisation (day care), out-patient and home-based care. Patients receiving treatment from more than one team member were classified as having 'multiple input'.

Inter-rated agreement for diagnosis based on an independent review of case-notes was 0.89 and for demographic details were 0.96 . Interrater correlation for the GAF was 0.9.

\section{Findings}

There were 235 patients in 'active contact' with the service on the day of the census. The case mix was psychotic disorders 53 (23\%), affective disorders 102 (43\%), anxiety adjustment disorders $43(18 \%)$ and other disorders $37(15 \%)$.

There were ten in-patients (one was placed in the main hospital). No patients were detained under the Mental Health Act. Twenty-seven patients were involved in the partial hospitalisation programme, 111] received home-based treatment and 79 out-patient treatment.

Global level of functioning was associated with treatment setting (ANOVA; $F(3,232)=10.2, P<0.005$ ) (Table 1). There was no association between age or gender and treatment setting, but patients in the partial hospitalisation programme were significantly more likely than other patients to live alone (15/27; $\chi=7.7 ;$ d.f. $=1 ; P<0.025)$.

The association between allocated keyworkers and diagnosis is shown in Table 2. CPNs were in contact with a total of 86 patients of whom $70(80 \%)$ had severe, longterm disorders ranging from psychosis to personality problems. Patients with multiple input (mean GAF=52; ANOVA, $F(4,214)=3.8$; $P<0.02)$ were significantly more impaired than those with a single key-worker (mean GAF=58).

\section{Comment}

This study is an evaluation of a UK community based mental health service which is not based in primary care. As with a one-day census a cross-sectional evaluation can provide information about workloads, diagnoses and treatment setting while requiring no additional resources to implement (Lelliott \& Strathdee, 1992). The disadvantage of a cross-sectional evaluation is that it cannot assess change nor the extent to which the service meets the needs of its target population.

Sixty-six per cent of the active cases of the multidisciplinary team consisted of individuals with psychotic or affective disorders which compares favourably with psychiatric services based in primary care $(45 \%)$ or hospital $(56 \%)$ (Jackson et al, 1993). Patients with psychotic disorders received more intenstve input (including day care in combination with frequent key-worker sessions and full or partial hospitalisation) than the other patients. Eighty per cent of patients with poor global functioning (GAF less than 40) were supported in the community with partial hospitalisation, home-based care (provided by medical as well as non-medical staff) or less often with treatment at an out-patient clinic. These findings are in marked contrast to reports that community mental health centres focus on the 'worried well' rather than the evaluation and treatment of the severely mentally ill (Pardes, 1990).

As expected, in-patients were more impaired than other patients in contact with the service. The number of in-patients on the day of the census (ten) was higher than usual for this service (the median bed occupancy in 1992 was five) but was similar to that found by Dean \& Gadd (1990) in a better resourced hometreatment service. The philosophy of this service concurs with Muijen et al, (1992) so that in-patient care remains vital for severely psychotic or disturbed patients even when alternattve community support services have been developed.

Muijen et al, (1992) found that single patients were particularly likely to be admitted to hospital. In this study those living alone were not more likely than other patients to be in-patients but they were more likely to be in the partial hospitalisation programme. Partial hospitalisation programmes run from the admission unit may be particularly beneficial to socially isolated severely ill patients. This flexdble alternative to hospitalisation is under-used in Britain, but has had a significant impact on bed usage in this service and services in the USA (Klar et al, 1982).

In this service the CPNs had a case-mix similar to the psychiatrists with both professionals acting as co-workers in treating severely disabled or psychotic patients in the community. Furthermore CPN input to these individuals was intensive and assertive extending far beyond the administration of 
depot medication. This finding contrasts with a recent review (Marks, 1992) suggesting that CPNs treat more patients with neurotic disorders. Unlike the trend reported elsewhere in the UK (Marks, 1992), the CPNs in this service do not take direct referrals from primary care. All referrals are sent to the multidisciplinary team and keyworker input is provided by the most appropriate professional. Using this system both the CPNs and the psychiatrists appear to be targeting their skills more clearly towards those with long-term severe disorders.

This study suggests that mental health service resources were being targeted at those individuals with the greatest need for care. This finding undermines fears that community services cannot prioritise people with severe mental illness. Operation diversity (for example assertive outreach and partial hospitalisation programmes) appears to contribute significantly towards achieving this prioritisation. However maintaining the CPNs within the secondary care services (rather than allowing their relocation to primary care settings) seems to be equally important in enabling this community service to meet its objectives.

\section{References}

AMERICAN PSYChIATRIC Association (1987) Diagnostic and Statistical Manual of Mental Disorders (3rd edn, revised) (DSM-III-R). Washington DC: APA.
DEAN, C. \& GADD, E. M. (1990) Home treatment for acute psychiatric lliness. British Medical Joumal, 301. 1021-1023.

JACKSON G., GATOR, R., GOLDBERG, D., TANTUM, D. et al (1993) A new community mental health team based in primary care. British Journal of Psychiatry. 162. 375-384.

KLAR, H., FRANCES, A. R., CLARKIN, J. (1982) Selection criteria for partial hospitalisation. Hospital \& Community Psychiatry. 33, 929-933.

Leunotr, P., \& STRATHDEe, G. (1992) The one day census in clinical audit. Psychiatric Bulletin, 16, 614-615.

MARKS, I. Innovations in mental health care delivery. British Journal of Psychiatry, 160 589-597.

MuJJen, M., Marks, I. ConNolly, J., \& Audin, B. (1992) Home-based care and standard hospital care for patients with severe mental illness: a randomised controlled trial. British Medical Journal, so4, 749-754.

PARDES, H. (1990) The demise of a major innovation. In Mental Health Care Delivery (eds. Marks I \& Scott R.) Cambridge: Cambridge Untversity Press (1990).

SCOTt, J., NORMANTON, M. \& MCKENNA, J. (1992) Developing a community orientated mental health service. Psychiatric Bulletin, 16, 150-152.

THORNICROFT, G. \& BEBBington, P. (1989) Deinstitutionalisation - from hospital closure to service development. British Journal of Psychiatry. 165, 739-753.

Jon Spear, Research Registar, St Nicholas Hospital, Gosforth, Newcastle upon Tyne NE3 3XT, Andrew Cole, Consultant Psychiatrist, The Grange, Grange Avenue, Benton, Newcastle upon Tyne NE12 9PN; and *Professor Jan Scott, University Department of Psychiatry, Newcastle upon Tyne NE1 4LP

"Correspondence 